Pesq. Vet. Bras. 29(3):229-232, março 2009

\title{
Freqüência de anticorpos homólogos anti-Borrelia burgdorferi em eqüinos na mesorregião metropolitana de Belém, Estado do Pará ${ }^{1}$
}

\author{
Katiany R. Galo², Adivaldo H. Fonseca ${ }^{*}$, Renata C. Madureira ${ }^{3}$ e José D. \\ Barbosa Neto ${ }^{2}$
}

\begin{abstract}
Galo K.R, Fonseca A.H., Madureira R.C. \& Barbosa Neto J.D. 2009. [Occurrence of homologous anti-Borrelia burgdorferi antibodies in equines in the metropolitan mesorregion of Belém, State of Para, Brazil.] Freqüência de anticorpos homólogos anti-Borrelia burgdorferi em eqüinos na mesorregião metropolitana de Belém, Estado do Pará. Pesquisa Veterinária Brasileira 29(3):229-232. Departamento de Epidemiologia e Saúde Pública, Instituto de Veterinária, Universidade Federal Rural do Rio de Janeiro, Seropédica, RJ 23890-000, Brazil. E-mail: adivaldo @ ufrri.br

Spirochaetes transmitted by ticks are microorganisms of worldwide distribution, which infect wild, domestic animals and human beings. A total of 300 equine sera from four municipalities: Ananideua (58), Belém (61), Castanhal (131), and Santa Izabel do Pará (50), were evaluated for Borrelia burgdorferi by an Elisa test. There were no significant differences $(P<0.05)$ among municipalities, breed, sex or husbandry. A total of $80(26.7 \%)$ horses were $B$. burgdorferi positive with titles of 1:800, $72(90 \%)$ horses, 1:1.600, $6(7.5 \%)$ horses, and 1:3.200, $2(2.5 \%)$ horses. The results were similar to those in the USA, where related frequencies ranged from 7 to $75 \%$ in asymptomatic seropositive horses. The presence of anti-B.burgdorferi homologous antibodies in horses from four municipalities in the metropolitan mesorregion of Belém suggests the possibility of occurrence of human cases in the region.
\end{abstract}

INDEX TERMS: Borrelia burgdorferi, Spirochaetacae, horses, serology.

RESUMO.- Espiroquetas transmitidas por carrapatos são microrganismos de ampla distribuição geográfica e acometem animais silvestres, domésticos e seres humanos. Procedeu-se a análise sorológica de 300 soros de eqüinos onde 58 animais eram do município Ananideua, 61 eram de Belém, 131 de Castanhal e 50 eram do município de Santa Izabel do Pará para Borrelia burgdorferi através do teste ELISA indireto. Não foram observadas diferenças significativas $(P<0,05)$ entre os municípios, nem quanto à raça, sexo e função dos animais. Um total de 80 $(26,7 \%)$ animais foram positivos para $B$. burgdorferi com

\footnotetext{
${ }^{1}$ Recebido em 8 de junho de 2007.

Aceito para publicação em 3 de novembro de 2008.

2 Escola de Medicina Veterinária, Campus Castanhal, Universidade Federal do Pará, Rua Maximino Porpino 1000, Castanhal, PA 68743080, Brasil.

${ }^{3}$ Departamento de Epidemiologia e Saúde Pública, Instituto de Veterinária, Universidade Federal Rural do Rio de Janeiro, Seropédica, RJ 23890-000, Brasil. *Autor para correspondência. adivaldo@ufrrj.br
}

os títulos de 1:800, 72 (90\%) eqüinos; 1:1.600, 6 (7,5\%) eqüinos; e 1:3.200, 2 (2,5\%) eqüinos. Os resultados observados foram similares aos descritos nos EUA, onde foram relatadas freqüências de soropositivos variando entre 7 e $75 \%$ em eqüinos assintomáticos. A presença de anticorpos homólogos contra $B$. burgdorferi em eqüinos na mesorregião metropolitana de Belém é indicativo da ampla distribuição do agente e da possibilidade de ocorrerem casos humanos deste agente na região.

TERMOS DE INDEXAÇÃO: Borrelia burgdorferi, Spirochaetacae, eqüinos, sorologia.

\section{INTRODUÇÃO}

Hemoparasitas do gênero Borrelia Swellengrebel, 1907 acometem diversas espécies de animais domésticos e silvestres, incluindo equídeos. O diagnóstico é um procedimento difícil, pois as manifestações clínicas, quando presentes, são similares a outras doenças e o imunodiagnóstico necessita de padronização para cada espécie 
animal (Parker \& White 1992, Soares et al. 2000). O estudo de borreliose em animais no Brasil tem sido realizado através do encontro ocasional de espiroquetas circulantes ou de análises sorológicas, sendo o ensaio de imunoadsorção enzimática (ELISA) indireto, a técnica empregada (Fonseca et al. 1996).

As espécies $B$. theileri e $B$. burgdorferi são comumente reportadas para eqüinos, sendo a primeira cosmopolita e a segunda restrita ao hemisfério norte. A infecção por $B$. burgdorferi em animais é geralmente assintomática, porém pode produzir sinais clínicos como perda de peso, claudicação esporádica, laminite, aumento articular e sinais neurológicos como depressão e mudança de comportamento (Cohen \& Cohen 1990, Parker \& White 1992).

Os animais domésticos atuam como carreadores de vetores de Borrelia sp. para o peridomicilio (Anderson, 1988), enquanto os silvestres caracterizam-se como reservatórios naturais, não apresentando sintomatologia clínica (Soares et al. 2000). Este trabalho teve como objetivo, investigar a freqüência de eqüinos soropositivos para anticorpos da classe IgG, homólogos contra Borrelia burgdorferi cepa G39/40 através do ensaio de imunoadsorção enzimática (ELISA) indireto na mesorregião metropolitana de Belém, Estado do Pará.

\section{MATERIAL E MÉTODOS}

\section{Local e animais examinados}

No período de agosto a novembro de 2005 foram coletadas e analisadas 300 amostras de sangue de eqüinos hígidos com idades que variavam entre sete meses e 23 anos, provenientes de quatro municípios da mesorregião metropolitana de Belém (Quadro 1), distribuídos em 23 propriedades ou pertencentes a carroceiros. As raças analisadas foram: Andaluz $(n=1)$, Árabe puro $(n=9)$, Brasileiro de Hipismo $(n=14)$, Manga Larga $(n=55)$ Marajoara $(n=10)$, Paint Horse $(n=1)$, Pampa $(n=1)$, Poney $(n=1)$, Puro Sangue Inglês $(n=3)$, Puruca $(n=11)$, Quarto de Milha $(n=13)$ e 181 eqüinos de raça não definida.

\section{Quadro 1. Número de amostras de soro de eqüinos, conforme o município}

Municípios de origem dos eqüinos Número de amostras

Ananideua
Belém
Castanhal
Santa Izabel do Pará

Santa Izabel do Pará

Os animais foram classificados quanto ao sexo, raça (animais de raça definida e mestiços) e de acordo com a função, tendo sido divididos entre animais destinados para esporte e para trabalho. Os animais destinados ao esporte constituíam eqüinos da cavalaria da Polícia Militar do Pará utilizados para equoterapia e animais de haras destinados à vaquejada, exposição, além de animais para fins reprodutivos. Os animais destinados ao trabalho eram pertencentes à carroceiros ou em fazendas para manejo do gado bovino.

As amostras de soro sanguíneo foram coletadas através da venopunção jugular, com agulha descartável 25x8mm, após anti-sepsia com álcool iodado. Foram utilizados para a coleta, tubos tipo vacutainer, colhendo-se um volume de aproximada- mente $7 \mathrm{~mL}$. Após a coleta, as amostras foram mantidas em temperatura ambiente até a retração do coágulo e transportadas ao Laboratório de Investigação e Diagnóstico de Enfermidades dos Animais (LIDEA) ou ao Centro de Diagnóstico Veterinário (CEDIVET, Castanhal), Universidade Federal do Pará (UFPA), onde foram submetidas à centrifugação (Centrífuga CELM®) a 3000rpm durante 5 minutos para obtenção da fração sérica e identificação, aliquotadas em tubos tipo Eppendorf e armazenados a $-20^{\circ} \mathrm{C}$ para posterior análise. As análises sorológicas foram realizadas no Laboratório de Doenças Parasitárias do Convênio "Projeto Sanidade Animal Embrapa/ UFRRJ".

\section{Anticorpos homólogos contra Borrelia burgdorferi}

As amostras coletadas foram analisadas através do ELISA indireto padronizado por Salles et al. (2002). Na realização do ensaio para detectar anticorpos da classe IgG homólogos contra $B$. burgdorferi latu sensu, o antígeno de $B$. burgdorferi stricto sensu cepa G39/40 foi diluído a $20 \mathrm{mg} / \mathrm{mL}$ em tampão carbonato pH 9,6, para a sensibilização de microplacas de poliestireno com 96 orifícios (M-4043, Sigma Chemical), que foram incubadas em câmara úmida a $4^{\circ} \mathrm{C}$ overnight.

Os soros testes, bem como os oito soros controles negativos foram diluídos a 1:800, e o soro controle positivo foi diluído em série, a partir de 1:800 até 1:102400, todos em PBS T 20; esta etapa do ensaio foi incubada por 90 minutos em câmara úmida a temperatura ambiente e lavada como a anterior. Foi adicionado às placas conjugado $\lg G$ de coelho anti lgG eqüina ligado à fosfatase alcalina (Sigma Chemical) na diluição de 1:1000 em PBS T 20 e incubado por 1 hora em câmara úmida à temperatura ambiente. As placas foram forradas com a solução reveladora composta pelo substrato para-nitro-fenil-fosfato de sódio (PNPP) (Sigma Chemical) diluído em tampão glicina $\mathrm{pH} 10,5$ na concentração de $1 \mathrm{mg} / \mathrm{mL}$. Estas permaneceram à temperatura ambiente até a revelação e momento de leitura em espectrofotômetro para microplacas de 96 orifícios (Microplate Reader model 550, Bio-Rad Laboratories), utilizando filtro para comprimento de onda de $405 \mathrm{hm}$. Em todas as fases do ensaio foram utilizados $200 \mathrm{~mL}$ de solução por orifício. A linha de corte do ensaio foi estabelecida pela média aritmética dos valores de densidade óptica dos soros controles negativos mais três vezes o desvio padrão destes.

Para análise estatística, foram utilizados os testes não paramétricos qui-quadrado e Ficher, por meio do programa computacional SAS/STAT (6 ${ }^{a}$ versão).

\section{RESULTADOS}

O exame sorológico de anticorpos da classe IgG antiBorrelia burgdorferi analisados através do ensaio ELISA indireto mostrou que dos 300 eqüinos estudados, $26,7 \%$ $(\mathrm{n}=80)$ foram positivos, sendo que $72(24 \%)$ apresentaram título de $1: 800$, seis $(2,0 \%)$ título de $1: 1600$ e dois $(0,6 \%)$ título de $1: 3200$, enquanto $220(73,3 \%)$ soros foram negativos. A análise de freqüência, número e títulos da epidemiologia sorológica estão representados no Quadro 2.

De acordo com os municípios estudados, não houve diferença significativa $(P<0,05)$ nos testes Qui-quadrado e Fisher, sendo que a freqüência foi de $27,6 \% \mathrm{em}$ Ananideua; 31,1\% em Belém, 23,7\% em Castanhal e 28\% em Santa Izabel do Pará conforme descrito no Quadro 3. 
Quadro 2. Freqüência e títulos dos soros de 300 eqüinos, da mesorregião metropolitana de Belém - PA para pesquisa de anticorpos homólogos da classe IgG, reagentes contra Borrelia burgdorferi

\begin{tabular}{ccccc}
\hline \multicolumn{5}{c}{ Freqüência } \\
\hline Título & Positivos $(\mathrm{n})$ & Relativa & Absoluta & Negativos (n) \\
\hline $1: 800$ & 72 & $90 \%$ & $24 \%$ & - \\
$1: 1600$ & 06 & $7,5 \%$ & $2 \%$ & - \\
$1: 3200$ & 02 & $2,5 \%$ & $0,6 \%$ & - \\
Total & 80 & $100 \%$ & $26,7 \%$ & - \\
Positivos & & $(80 / 80)$ & $(80 / 300)$ & \\
Total & - & - & $73,3 \%$ & \\
Negativos & & & $(220 / 300)$ & 220
\end{tabular}

Quadro 3. Freqüência sorológica nos diferentes municípios de anticorpos homólogos anti-B. burgdorferi em eqüinos da mesorregião metropolitana de Belém, PA, determinado pelo ELISA indireto Municípios $(n=300)$

\begin{tabular}{|c|c|c|c|c|c|}
\hline & Ananindeua & Belém & Castanhal & Santa Izabel & Total \\
\hline Positivos & $\begin{array}{l}27,6 \% \\
(16 / 58)\end{array}$ & $\begin{array}{l}31,1 \% \\
(19 / 61)\end{array}$ & $\begin{array}{c}23,7 \% \\
(31 / 131)\end{array}$ & $\begin{array}{c}28 \% \\
(14 / 50)\end{array}$ & $\begin{array}{c}26,7 \% \\
(80 / 300)\end{array}$ \\
\hline Negativos & $\begin{array}{l}72,4 \% \\
(42 / 58)\end{array}$ & $\begin{array}{l}68,9 \% \\
(42 / 61)\end{array}$ & $\begin{array}{c}76,3 \% \\
(100 / 131)\end{array}$ & $\begin{array}{c}72 \% \\
(36 / 50)\end{array}$ & $\begin{array}{c}73,3 \% \\
(220 / 300)\end{array}$ \\
\hline Total & $\begin{array}{c}100 \% \\
(58 / 58)\end{array}$ & $\begin{array}{l}100 \% \\
(61 / 61)\end{array}$ & $\begin{array}{c}100 \% \\
(131 / 131)\end{array}$ & $\begin{array}{c}100 \% \\
(50 / 50)\end{array}$ & $\begin{array}{c}100 \% \\
(300 / 300)\end{array}$ \\
\hline
\end{tabular}

Na análise dos dados, foi observado que 13,7\% ( $n=41)$ das fêmeas e $13 \%(n=39)$ dos machos foram reagentes. Em relação as raças, verificou-se que $9 \%(n=27)$ dos animais de raças definidas e $17,7 \%(n=53)$ dos animais mestiços foram positivos. Não houve diferença significativa $(P<0,05)$ entre os diferentes sexos e raças.

Com relação à função, os animais destinados a esporte apresentaram positividades de $24,8 \%(n=26)$, os de trabalhos foi de 27,7\% ( $n=54)$, representados no Quadro 4. Também não houve diferença significativa $(P<0,05)$ em relação à função desempenhada pelos animais.

Quadro 4. Freqüência sorológica, de acordo com a função dos animais, de anticorpos homólogos anti-Borrelia burgdorferi em eqüinos da mesorregião metropolitana de Belém, PA, determinado pelo ELISA indireto

\begin{tabular}{cccccc}
\hline \multicolumn{4}{c}{ Função $(\mathrm{n}=300)$} \\
\hline & \multicolumn{2}{c}{ Esporte } & & \multicolumn{2}{c}{ Trabalho } \\
\cline { 2 - 3 } \cline { 5 - 6 } Pelativa & Absoluta & & Relativa & Absoluta \\
\hline \multirow{2}{*}{ Positivos } & $24,8 \%$ & $8,7 \%$ & & $27,7 \%$ & $18 \%$ \\
& $(26 / 105)$ & $(26 / 300)$ & & $(54 / 195)$ & $(54 / 300)$ \\
Totalivos & $75,2 \%$ & $26,3 \%$ & & $72,3 \%$ & $47 \%$ \\
& $(79 / 105)$ & $(79 / 300)$ & & $(141 / 195)$ & $(141 / 300)$ \\
& $100 \%$ & $35 \%$ & & $100 \%$ & $65 \%$ \\
& $(105 / 105)$ & $(105 / 300)$ & & $(195 / 195)$ & $(195 / 300)$
\end{tabular}

\section{DISCUSSÃO}

A freqüência de anticorpos homólogos anti-B.burgdorferi encontrada no presente estudo foi de $26,7 \%$ (80/300), superior ao observado por Salles et al. (2002), que ao analisarem soros de eqüinos no Estado do Rio de Janeiro por meio do ensaio ELISA indireto, encontraram 9,8\% (49/ $501)$ dos animais positivos. No entanto, Madureira et al.
(2007), utilizando a mesma técnica, verificou 28,1\% (216/ 769) de soropositividade em eqüinos provenientes dos municípios Três Rio e Vassouras, também no Estado do Rio de Janeiro.

No presente estudo, não foi observada diferença significativa entre as freqüencias de animais soropositivos dos diferentes municípios e o resultado corrobora com os encontrados em outras espécies de animais domésticos no Brasil, como bovinos (Fonseca et al. 1996) e caninos (O'Dwyer et al. 2004). Resultados semelhantes foram reportados nos Estados Unidos da América, onde foram observadas soropositividade que variavam entre 12 e $75 \%$ em eqüinos sem sintomatologia clínica para borreliose de Lyme (Bernard et al. 1990, Cohen et al. 1988, Cohen et al. 1992, Marcus et al. 1985, Parker \& White 1992).

No Brasil ainda não foi possível isolar Borrelia sp. devido à exigência nutricional desta espiroqueta (Soares et al. 2000, Abel et al. 2000) além da alta freqüência de contaminação por fungos e outras bactérias no meio BSK, mesmo quando adicionado a antibióticos (Oliveira et al. 2004). No entanto, foi possível visualizar microorganismos semelhantes a Borrelia sp. em culturas de soro humano, marsupiais, roedores silvestres, bovinos e culturas de carrapatos (Yoshinari et al. 1997). Recentemente, verificou-se através de esfregaço sanguíneo, espiroquetídeos com formas típicas de Borrelia theileriem bubalinos no município de Castanhal, Estado do Pará, constatando o primeiro relato de infecção por Borrelia sp. em Bubalis bubalis no Brasil (Scofield et al. 2005).

A estreita associação filogenética entre $B$. theileri e outras espiroquetas do gênero Borrelia responsáveis pelas manifestações clínicas da borreliose de Lyme e pela febre recorrente, sugerem a possibilidade de reações cruzadas entre esses agentes. Rogers et al. (1999) observaram reação cruzada entre $B$. burgdorferi, $B$. coriaceae e B. theileri.

Yoshinari et al. (1997) realizaram testes com cepas européias (B. garinii e B. afzelli) e norte americana ( $B$. burgdorferi) e compararam com Borrelia sp. existentes em nosso meio, concluindo que os microrganismos verificados no Brasil são distintos das anteriormente citadas. Mantovani et al. (2007) descreveram um quadro clínico em seres humanos no Brasil, cujas características mimetizam a clássica Borreliose de Lyme dos Estados Unidos e Europa e a relacionaram como sendo uma zoonose transmitida por carrapatos. Estes autores discutiram a provável etiologia da Borreliose de Lyme no Brasil e relataram a concomitância do diagnóstico de microrganismos semelhantes a Espiroquetas, Micoplasma e/ou Clamydias nestes pacientes. Owen (2006), publicou artigo propondo o sinergismo entre Borrelia sp. e co-infecção com outros microrganismos transmitidos por carrapatos como explicação para as diferentes variações da Borreliose de Lyme. Palácios et al. (1999) realizando estudos em indivíduos que apresentavam sinais clínicos compatíveis com a borreliose de Lyme, utilizando o ensaio ELISA e Western blotting com soro e fluido cerebral 
observaram que na Colômbia a espiroqueta existente é de genoespécie distinta de $B$. burgdorferi latu sensu.

Em relação à função dos animais, não foi possível verificar diferença significativa entre as freqüências encontradas em animais de trabalho, que são aqueles que têm um menor controle efetivo de ectoparasitas e os de esporte. Salles et al. (2002) em estudos efetuados em eqüinos no Estado do Rio de Janeiro os animais mantidos sob rígido controle de ectoparasitas apresentaram $0,9 \%$ de soropositividade para $B$. burgdorferi, contrastando com os animais que viviam em locais sem nenhum tipo controle, que apresentaram $42,9 \%$. No presente estudo, a maioria dos animais estava infestado por carrapatos, no entanto, não foi possível determinar quais as espécies existentes, e na maioria das propriedades não havia controle preventivo eficiente. Alguns faziam banhos carrapaticidas que variavam de semanal a mensal, outros só realizavam quando havia uma alta infestação de carrapatos.

No presente trabalho não houve diferença significativa entre a distribuição da prevalência de anticorpos antiB.burgdorferi quanto a raças e sexos. Estes resultados estão de acordo com os observados por Salles et al. 2002, O'dwyer et al. 2004 e Madureira et al. 2007.

Marcus et al. (1985) observaram que nos EUA a freqüência de $B$. burgdorferi em eqüinos foi maior em áreas endêmicas que em áreas não endêmicas com soropositividade de $24 \%$ e $2 \%$, respectivamente, não havendo diferença significativa entre raças e sexo.

A epidemiologia e os aspectos clínicos das borrelioses em animais e no homem apresentam características variadas de acordo com as regiões, devido à existência distinta de espécies, genoespécies, e cepas de Borrelia, carrapatos vetores, interação vetor-patógeno e ecossistemas distintos (Baraton et al. 1992, Yoshinari et al. 1997), sendo os animais domésticos competentes reservatórios de Borrelia sp. no ambiente domiciliar (Mather et al. 1994).

\section{CONCLUSÃO}

A presença de anticorpos homólogos contra Borrelia burgdorferi em eqüinos na mesorregião metropolitana de Belém é indicativo da ampla distribuição de Borrelia sp. e da possibilidade de ocorrerem casos humanos de borreliose.

Agradecimentos.- À instituição FAPERJ pelo auxílio financeiro.

\section{REFERÊNCIAS}

Abel I.S., Marzagão G., Yoshinari N.H. \& Schumaker T.T. 2000. Borrelialike Spirochetas recovered from ticks and small mammals collected in the Atlantic Forest Reserve, Cotia County, state of São Paulo, Brazil. Mem. Inst. Oswaldo Cruz 95(5):621-624.

Anderson J.F. 1988. Mammalian and avian reservoirs for Borrelia burgdorferi. Ann. N. Y. Acad. Sci. 539:190.

Baranton G., Postic D. \& Saint Giros I. 1992. Delineation of Borrelia burgdorferi sensu stricto, Borrelia garinii sp. nov., and VS461 associated with Lyme borreliosis. Int. J. Syst. Bacteriol. 42(2):378383.

Bernard W.V., Cohen D., Bosler E. \& Zamos D. 1990. Serologic survey for Borrelia burgdorferi antibody in horses referred to a mid-Atlantic Veterinary Teaching Hospital. J. Am. Vet. Med. Assoc. 196(8):1255-1258.

Cohen D., Bosler E.M., Bernard W., Meirs li D., Eisner R. \& Schulze T.C. 1988. Epidemiologic studies of Lyme disease in horses and their public health significance. Ann. New York Acad. Sci. 539:244-257.

Cohen N.D. \& Cohen D. 1990. Borreliosis in horses: A comparative review. Compendium 12(10):1449-1458.

Cohen N.D., Heck F.C., Heim B., Flad D.M., Bosler E.M. \& Cohen D. 1992. Seroprevalence of antibodies to Borrelia burgdorferi in a population of horses in central Texas. J. Am. Vet. Med. Assoc. 201(7):1030-1034.

Fonseca A.H., Ishikawa M.M., Soares C.O., Masard C.L. \& Yoshinari N.H. 1996. Lyme borreliosis serology in cattle in Brazil. Revta. Univ. Rural, Sér. Ciênc. da Vida 18(1/2):85-89.

Madureira R.C., Corrêa F.N., Cunha N.C., Guedes Jr D.S \& Fonseca A.H. 2007. Ocorrência de anticorpos homólogos anti-Borrelia burgdorferi em eqüinos de propriedades dos municípios de Três Rios e Vassouras, estado do Rio de Janeiro. Revta Bras. Ciênc. Vet. 14(1):43-47.

Matovani E., Costa I.P., Gauditano G., Bonold V.L.N., Higuchi M.L. \& Yoshinari N.H. 2007. Description of Lyme disease-like syndrome in Brazil. Is it a new tick borne disease or Lyme disease variation? Braz. J. Med. Biol. Res. 40(4):443-456.

Marcus L.C., Patterson M.M., Gilfillan R.E. \& Urband P.H. 1985. Antibodies to Borrelia burgdorferi in New England horses: Serologic survey. Am. J. Vet. Res. 46(12):2570-2571.

Mather T.N., Fish D. \& Coughlin R.T. 1994. Competence of dogs as reservoirs for Lyme disease spirochetes (Borrelia burgdorferi). J. Am. Vet. Med. Assoc. 205(2):186-188.

Oliveira A., Fonseca A.H., Ishikawa M.M. \& Yoshinari N.H. 2004. Cinética do crescimento de Borrelia burgdorferi em diferentes meios de cultivo. Pesq. Vet. Bras. 24(2):61-64.

O'dwyer L.H., Soares C.O., Massard C.L., Souza J.C.P., Flausino W. \& Fonseca A.H. 2004. Soroprevalência de Borrelia burgdorferi latu sensu associada à presença de carrapatos em cães de áreas rurais do estado do Rio de Janeiro, Brasil. Ciência Rural 34(1):201-205.

Owen D.C. 2006. Is Lyme disease always poly microbial? - The jigsaw hypotheis. Medical Hypoteses 67(4):860-864.

Parker J.L. \& White K.W. 1992. Lyme borreliosis in cattle and horses: A review of the literature. Cornell Vet. 82:253-274.

Palácios R., Osorio L.E., Giraldo L.E., Torres A.J., Philipp M.T. \& Ochoa M.T. 1999. Positive IgG Western Blot for Borrelia burgdorferi in Colombia. Mem. Inst. Oswaldo Cruz 94(4):499-503.

Rogers A.B., Smith R.D. \& Kakoma I. 1999. Serologic cross-reactivity of antibodies against Borrelia theileri, Borrelia burgdorferi and Borrelia coriaceae in cattle. Am. J. Vet. Res. 60 (6):694-697.

Salles R.S., Fonseca A.H., Scofield A., Madureira R.C. \& Yoshinari N.H. 2002. Sorologia para Borrelia burgorferi latu sensu em eqüinos no Estado do Rio de Janeiro. Hora Vet., Porto Alegre, 22(127):46-49.

Scofield A., Costa C.M., Barbosa J.D. \& Fonseca A.H. 2005. Ocorrência de Borrelia sp. em Búfalo (Bubalus bubalis) no município de Castanhal, Estado do Pará, Brasil. VI Congresso Brasileiro de Buiatria, Búzios, RJ. Assoc. Bras. Buiatria. (CD-Room)

Soares C.O., Ishikawa M.M., Fonseca A.H. \& Yoshinari N.H. 2000. Borrelioses, agentes e vetores. Pesq. Vet. Bras. 20(1):1-19.

Yoshinari N.H., Barros P.J.L., Bonoldi V.L.N., Ishikawa M., Battesti D.M.B., Pirana S., Fonseca A.H. \& Schumaker T.T. 1997. Perfil da Borreliose de Lyme no Brasil. Revta Hosp. Clin. Fac. Med. São Paulo 52(2):111-117. 